\title{
Correction to: Compressed Sensing in Imaging and Reconstruction - An Insight Review
}

\author{
K. Sreekala and E. Krishna Kumar
}

\section{Correction to: \\ Chapter "Compressed Sensing in Imaging and Reconstruction - An Insight Review" \\ in: A. Abraham et al. (Eds.): \\ Intelligent Systems Design and Applications, AISC 941, https://doi.org/10.1007/978-3-030-16660-1_76}

In the original version of the chapter, the following belated correction has been incorporated: The reference "Zarnaghi Naghsh, N., et al.: CS for microwave breast cancer imaging. IET Sig. Process. 12, 242-246 (2018)" has been changed to "Zarnaghi Naghsh, N., et al.: Compressive sensing for microwave breast cancer imaging. IET Sig. Process. 12, 242-246 (2018) in reference [76]". 